\title{
Aroma-Loaded Microcapsules with Antibacterial Activity for Eco- Friendly Textile Application: Synthesis, Characterization, Release, and Green Grafting
}

\author{
Asma Sharkawy, ${ }^{\dagger}$ I. P. Fernandes, ${ }^{\ddagger}$ M. F. Barreiro, ${ }^{\ddagger}$ Alirio E. Rodrigues, ${ }^{*}, \S$ and Tamer Shoeib ${ }^{*},,^{\dagger},{ }_{\odot}$ \\ ${ }^{\dagger}$ Department of Chemistry, The American University in Cairo, New Cairo 11835, Egypt \\ ${ }^{\ddagger}$ Laboratory of Separation and Reaction Engineering (LSRE), Associate Laboratory LSRE/LCM, Polytechnic Institute of Bragança, \\ Campus of Santa Apolonia, 5300-253 Bragança, Portugal \\ ${ }^{\S}$ Laboratory of Separation and Reaction Engineering, Department of Chemical Engineering, Faculty of Engineering, University of \\ Porto, Porto 4200-465, Portugal \\ "Centre for Analytical Science, Department of Chemistry, Loughborough University, Loughborough, Leicestershire LE11 3TU, U.K.
}

Supporting Information

\begin{abstract}
Fragrant and antimicrobial properties were conferred to cotton fabrics following microencapsulation using green materials. Limonene and vanillin microcapsules were produced by complex coacervation using chitosan/gum Arabic as shell materials and tannic acid as hardening agent. The effect of two emulsifiers; Span 85 and polyglycerol polyricinoleate (PGPR), on the encapsulation efficiency (EE\%), microcapsule's size and morphology, and cumulative release profiles was studied. The mean diameter of the produced microcapsules ranged between 10.4 and $39.0 \mu \mathrm{m}$, whereas $\mathrm{EE} \%$ was found to be

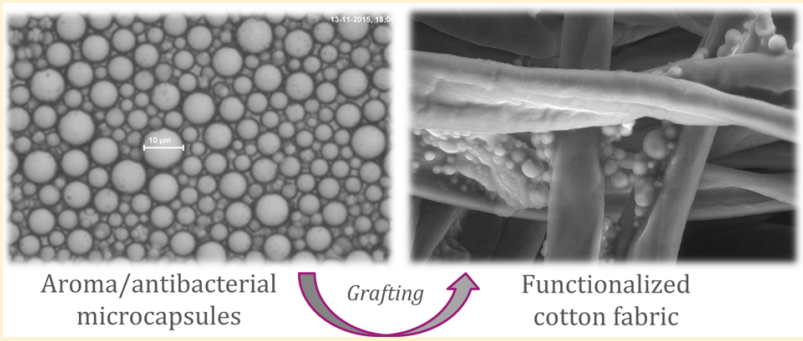
between $90.4 \%$ and $100 \%$. The use of Span 85 resulted in mononuclear morphology while PGPR gave rise to polynuclear structures, regardless of the core material (vanillin or limonene). The obtained microcapsules demonstrated a sustained release pattern; namely the total cumulative release of the active agents after 7 days at $37 \pm 1{ }^{\circ} \mathrm{C}$ was $75 \%, 52 \%$ and $19.4 \%$ for the polynuclear limonene microcapsules, the mononuclear limonene microcapsules and the polynuclear vanillin microcapsules, respectively. Grafting of the produced microcapsules onto cotton fabrics through an esterification reaction using citric acid as a nontoxic cross-linker followed by thermofixation and curing, was confirmed by SEM and FTIR spectroscopy. Standard antibacterial assays conducted on both microcapsules alone and impregnated onto the fabrics indicated a sustained antibacterial activity.
\end{abstract}

\section{INTRODUCTION}

The increase in the market competitiveness along with the diversity of consumers' demands has created a challenging environment in the textile industry sector. This subsequently led to the production of innovative textile products with advanced properties that enhance ergonomics, health, and safety. ${ }^{1}$ Innovative technologies in textiles have succeeded in offering a wide variety of fabrics with unprecedented functions. $^{2,3}$ The most common applications of functional textiles include the use of phase change materials, insect repellents, antimicrobials, fragrances, dyes and colorants, skin softeners and moisturizers, some medicines, and flame retardants. ${ }^{2,4-10}$

Enhancing the durability and prolonging the lifetime of functional textiles have been always one of the most challenging missions for textiles' manufacturers, owing to the fact that they are nondisposable and need to be washed after use. In this context, microencapsulation techniques have been known to provide textiles with long-lasting properties and added value. ${ }^{11}$ The process involves the coating of the active ingredient with one or more polymeric materials to form particles whose sizes range between 1 and $1000 \mu \mathrm{m} .{ }^{12,13}$ According to their internal structure, ${ }^{14}$ microcapsules can be classified into two main types, either reservoir or monolithic. Reservoir microcapsules can be either mononuclear or polynuclear (multinuclear), whereas the monolithic microcapsules are formed of a matrix with the active ingredient dispersed within it. ${ }^{11}$ Each microcapsule acts as a minute reservoir for the active ingredient which would be released under specific conditions. ${ }^{15}$ This process thus remarkably increases the durability and long-lastingness of the effect of the functional ingredient incorporated onto these textiles.

Nowadays, researchers and manufacturers are increasingly interested in green chemistry protocols, taking into account the growing public concern and awareness of the importance of the

Received: February 21, 2017

Revised: April 23, 2017

Accepted: April 25, 2017

Published: April 25, 2017 
utilization and application of safe and eco-friendly materials and processes. However, the majority of the commercially available microcapsules that are intended for textile applications are made of melamine-formaldehyde, urea-formaldehyde or phenol-formaldehyde resins. ${ }^{16,17}$ Regardless of the fact that these polymers are used because of their good thermal stabilities and their ability to be modified according to the desired release profiles, they represent a serious threat for the environment and human health. This is due to their nonrecyclable nature (thermosetting polymers) and also owing to the carcinogenicity and toxicity of formaldehyde. ${ }^{18}$ Thus, the replacement of such polymeric systems with safe and environmentally benign materials has become extremely important. ${ }^{19}$ Natural and natural-derived polymers, especially those presenting biocompatibility and biodegradability characteristics, are increasingly becoming promising alternatives to synthetic polymers, as they are known to be eco-friendly, abundant, and safe to human health. ${ }^{20,21}$

Complex coacervation is considered as one of the most suitable methods to encapsulate fragrances and flavors; it reduces or prevents the loss of the volatile compounds since it does not require high processing temperatures. ${ }^{22}$ It is a phase separation process that depends on the complexation between oppositely charged polymers via electrostatic attractions, formation of hydrogen bonds, or hydrophobic interactions. ${ }^{23}$ To increase microcapsules' integrity, a hardening agent is usually added in the last step of the coacervation process to consolidate the formed shells and stabilize their structure. ${ }^{24}$ Formaldehyde and glutaraldehyde are widely used, but since they are reported to be toxic, they became banned in some countries. $^{25}$ Therefore, the use of safe and eco-friendly alternatives has gained significant importance to substitute these conventional cross-linking agents. This is the case of tannic acid, a natural plant polyphenol, which has the ability to bind to polymers through hydrogen bonding and hydrophobic interactions. $^{26-28}$

The process of fixing the microcapsules onto textile substrates is another critical step in ensuring durability, washability, and the effectiveness of the added-value properties of the fabric. The adhesion methods involve the use of two main groups of binders: polymeric resins, with film-forming ability, and polyfunctional cross-linking agents. ${ }^{29}$ Although filmforming binders provide a three-dimensional network that strongly adheres microcapsules to the fabric, they may hinder the release of the encapsulated active agent and reduce the aroma intensity of the used fragrance microcapsules. ${ }^{30,31}$ Therefore, chemical grafting by means of polyfunctional cross-linkers is sometimes preferred. These chemical crosslinkers can be subdivided into formaldehyde based crosslinkers, e.g., formaldehyde and glutaraldehyde, and nonformaldehyde based cross-linkers, such as polycarboxylic acids. Grafting or cross-linking of microcapsules to cotton fabrics via polycarboxylic acids occurs covalently through an esterification reaction between their own carboxylic groups and hydroxyl groups present in the cotton cellulose and/or the polymeric materials of the microcapsules' shell. ${ }^{32,33}$

Fabrics of natural origins, such as cotton, are known to be more susceptible to colonization by invasive microbes than synthetic ones. ${ }^{19}$ This is due to their high hydrophilic and porous composition that tends to retain humidity, nutrients, and oxygen, thus offering an ideal environment for the growth of microorganisms. ${ }^{19,34}$ This results in unpleasant odors, transmission of diseases, and allergic responses in some individuals. Additionally, deterioration of fabrics in terms of color degradation, loss of elasticity and tensile strength, and interference with the dyeing and printing processes can occur. ${ }^{19}$ Hence, it is crucial to combat these undesired effects through imparting of effective antimicrobial additives to textiles. ${ }^{35,36}$

In this context, vanillin encapsulated in a polysulfone polymer and incorporated onto cotton fabrics was reported to provide the fabrics with durable aromatic properties and antibacterial activity. ${ }^{3}$ Rodrigues and co-workers used interfacial polymerization technology to encapsulate limonene in polyurethane-urea microcapsules for the purpose of producing durable fragrant fabrics. ${ }^{37}$ Sundrarajan also reported the preparation of limonene/gum Arabic microcapsules for textile application. ${ }^{36}$

In this work, the microencapsulation of vanillin and limonene by the complex coacervation method using chitosan/gum Arabic as encapsulants and tannic acid as the hardening agent was studied. To our knowledge, this is the first successful encapsulation of the cargo using this method, as the available literature on complex coacervation to date did not refer to the encapsulation of limonene and vanillin (in pure form and not vanilla oil) by the usage of chitosan and gum Arabic as the wall material pair. The impact of two emulsifiers (Span 85 and polyglycerol polyricinoleate (PGPR)) on the encapsulation efficiency and microcapsules' size and morphology was studied together with the characterization of the cumulative release profiles of limonene and vanillin. A strategy to achieve the immobilization of the produced limonene and vanillin microcapsules on cotton fabrics by using citric acid, an ecofriendly cross-linker, was developed, and the antibacterial activity of the microcapsules alone and impregnated onto the fabric was evaluated.

\section{EXPERIMENTAL SECTION}

2.1. Materials. Chitosan (degree of deacetylation $88-95 \%$ and molecular weight between 80000 and $200000 \mathrm{Da}$ ) from Bio Log Biotechnologie Und Logistik (Germany) and gum Arabic from Sigma-Aldrich were used as shell-forming materials. Vanillin and limonene, used as core agents, were purchased from Sigma-Aldrich. Pure corn oil, used as carrier for vanillin, was obtained from Sigma-Aldrich. Polyglycerol polyricinoleate (PGPR 4150) was a gift from Palsgaard (Denmark), and Span 85 was supplied from Sigma-Aldrich. Tannic acid was supplied by Merck. $0.1 \mathrm{~N}$ acetic acid, used to dissolve chitosan, was purchased from Sigma-Aldrich. nHexane, used as the microcapsules' washing medium and in the release studies, was supplied from Carlo Erba Reagents. Citric acid and sodium phosphate monobasic monohydrate were purchased from Sigma-Aldrich and were used in the chemical grafting reaction. Standard $100 \%$ cotton fabric was purchased from SDC Enterprises Limited, U.K.

2.2. Production of Microcapsules. Microcapsules were prepared by complex coacervation using a four-step process adapted from the literature with some modifications. ${ }^{38-40}$ In brief, the first step involved the dissolution of the biopolymers chitosan and gum Arabic. 1\% (w/v) chitosan solution was prepared by dissolving chitosan in $0.1 \mathrm{~N}$ acetic acid and left under magnetic stirring for $15 \mathrm{~h}$ to ensure complete dissolution. $2 \%(\mathrm{w} / \mathrm{v})$ gum Arabic solution was obtained by dissolving gum Arabic in deionized water with continuous magnetic stirring at $45^{\circ} \mathrm{C}$ for $2 \mathrm{~h}$. In the second step, the polymer solutions $(50 \mathrm{~mL}$ of the chitosan solution and $50 \mathrm{~mL}$ of the gum Arabic solution) were mixed together, and then a known amount of the core 
material (either vanillin or limonene) plus emulsifier was added. The corresponding used quantities, of both the core materials and the emulsifiers, in the six prepared formulations are shown in Table 1 .

Table 1. Chemical System of the Formulations ${ }^{a}$

\begin{tabular}{clll} 
formulation & active principle & \multicolumn{1}{c}{ carrier oil } & \multicolumn{1}{c}{ emulsifier } \\
1 & vanillin $(0.02 \mathrm{~g})$ & corn oil $(1 \mathrm{~g})$ & PGPR $(0.35 \mathrm{~g})$ \\
2 & vanillin $(0.12 \mathrm{~g})$ & corn oil $(4.5 \mathrm{~g})$ & PGPR $(0.6 \mathrm{~g})$ \\
3 & vanillin $(0.02 \mathrm{~g})$ & corn oil $(1 \mathrm{~g})$ & Span $85(0.35 \mathrm{~g})$ \\
4 & limonene $(1 \mathrm{~g})$ & $a$ & PGPR $(0.35 \mathrm{~g})$ \\
5 & limonene $(4.5 \mathrm{~g})$ & $a$ & PGPR $(0.6 \mathrm{~g})$ \\
6 & limonene $(1 \mathrm{~g})$ & $a$ & Span $85(0.35 \mathrm{~g})$
\end{tabular}

${ }^{a}$ No carrier oil was used.

The mixture was then emulsified at a speed rate of $8000 \mathrm{rpm}$ at $40{ }^{\circ} \mathrm{C}$ for $1 \mathrm{~min}$ with an Ultra-Turrax IKA DI 25 Basic. Taking into consideration that vanillin is a solid powder, it was previously dissolved in corn oil at $40{ }^{\circ} \mathrm{C}$ in a covered beaker for $10 \mathrm{~min}$ before being added to the mixture. The third step entailed the induction of complex coacervation by decreasing the $\mathrm{pH}$ value with $0.2 \mathrm{~N} \mathrm{HCl}$ and setting the stirring speed of the formed emulsion to $400 \mathrm{rpm}$. In this study, the $\mathrm{pH}$ was adjusted to 3.5 to maximize chitosan positive charge $(2.8<\mathrm{pH}$ $<4)$ and gum Arabic negative charge $(\mathrm{pH}>2.2) .^{38}$ After 30 min of continuous stirring, the temperature was gradually decreased from 40 to $5{ }^{\circ} \mathrm{C}$ with the help of an ice bath. The last step involved the hardening of the microcapsules by dropwisely adding $2 \mathrm{~mL}$ of a $10 \%(\mathrm{w} / \mathrm{v})$ tannic acid solution at $5{ }^{\circ} \mathrm{C}$ and stirring at $400 \mathrm{rpm}$ for $3 \mathrm{~h}$. The formed microcapsules were then separated by decantation, recovered, and stored in the form of a suspension for further analysis.

2.3. Characterization of Microcapsules. 2.3.1. Optical Microscopy. As a routine assay, the morphology of the obtained microcapsules was examined by optical microscopy by using a Leica DM 2000 optical microscope equipped with Leica Application Suite Interactive Measurement imaging software.

2.3.2. Particle Size Evaluation. Size distributions and mean particle size of the produced microcapsules were determined by laser diffraction with a Beckman Coulter laser diffraction particle size analyzer LS 230. The size distribution measurements were obtained in volume.

2.3.3. Encapsulation Efficiency. To determine the encapsulation efficiency of both vanillin and limonene, the nonencapsulated active agent was evaluated by GC-FID using a Varian CP-3800 gas chromatograph equipped with two CPWax 52CB bonded fused silica polar columns $(50 \mathrm{~m} \times 0.25$ mm with $0.2 \mu \mathrm{m}$ film thickness) and a Varian FID detector operated by the Saturn 2000 WS software. The used method comprised setting the injectors at $240{ }^{\circ} \mathrm{C}$ and the FID detector at $250{ }^{\circ} \mathrm{C}$. The carrier gas was helium $\mathrm{He} \mathrm{N} 60$ with a flow rate of $1 \mathrm{~mL} / \mathrm{min}$ and a split ratio of 1:50 was used.

For vanillin analysis, the oven temperature was kept isothermal at $50{ }^{\circ} \mathrm{C}$ for $5 \mathrm{~min}$ and then increased gradually from $50{ }^{\circ} \mathrm{C}$ up to $120{ }^{\circ} \mathrm{C}$ (rate of $10{ }^{\circ} \mathrm{C} / \mathrm{min}$ ), followed by a second gradual increase to $200{ }^{\circ} \mathrm{C}$ (rate of $2{ }^{\circ} \mathrm{C} / \mathrm{min}$ ). For limonene, the oven temperature was maintained isothermal at $175^{\circ} \mathrm{C}$ for $7 \mathrm{~min}$ and then increased to $220^{\circ} \mathrm{C}$ (rate of $10^{\circ} \mathrm{C}$ / min) with a hold of $5 \mathrm{~min}$. The samples for injection were prepared by taking $2 \mathrm{~mL}$ from the whole formulation, then mixed with $1 \mathrm{~mL}$ of $n$-hexane, followed by centrifugation at
$3000 \mathrm{rpm}$ for $5 \mathrm{~min}$. The collected supernatant was filtered through $0.2 \mu \mathrm{m}$ pore size polypropylene filter. Thereafter, a volume of $0.1 \mu \mathrm{L}$ was injected. All measurements were done in triplicate. Quantification was based on previously prepared calibration curves. The encapsulation efficiency (EE\%) was calculated according to the following equation:

$$
\mathrm{EE} \%=\frac{\operatorname{mass}(\text { total })-\operatorname{mass}(\text { nonencapsulated })}{\operatorname{mass}(\text { total })} \times 100
$$

where mass(total) is the mass of the loaded core material in the process in $\mathrm{g}$, and mass(nonencapsulated) is the mass of the nonencapsulated core material, as determined by GC-FID, in g.

2.3.4. Solid Content Determination. The solid content of the microcapsule's suspension was determined according to the European Standard EN 827, as described for water based adhesives. The test was done by placing about $1 \mathrm{~g}$, rigorously weighted, of the microcapsules' suspension on a watch glass (mass (initial)) and allowing it to dry in an oven at $100{ }^{\circ} \mathrm{C}$ for $30 \mathrm{~min}$, then placing it in a desiccator for $15 \mathrm{~min}$ and weighing the residual mass. The drying step was repeated until the difference between two consecutive weightings did not exceed $2 \mathrm{mg}{ }^{41}$ This value was considered the final mass (mass (final)). The solid content was calculated according to the following equation:

$$
\% \text { solid content }=\frac{\operatorname{mass}(\text { final })}{\operatorname{mass}(\text { initial })} \times 100
$$

2.4. Cumulative Release Profiles. The used method was adapted from a previously reported study. ${ }^{40}$ Briefly, vanillin and limonene microcapsules suspensions were first washed with deionized water and thereafter with $n$-hexane in order to remove all the nonencapsulated core material from the microcapsules. Then, volumes of $70 \mathrm{~mL}$ of washed microcapsules suspension were placed in sealed bottles containing a $30 \mathrm{~mL}$ of $n$-hexane and placed in an incubator at $37^{\circ} \mathrm{C}$ under a mild shaking speed of $100 \mathrm{rpm}$. At predetermined time intervals, samples ( $2 \mathrm{~mL}$ of the supernatant) were taken out of the incubating chamber, filtered through $0.2 \mu \mathrm{m}$ pore size polypropylene filter, and placed in a sealed vial for GC-FID analysis according to the procedure described in the section 2.3.3. In order to keep the final volume constant, $2 \mathrm{~mL}$ of $n$ hexane was added to the microcapsules' suspension in the sealed bottles to compensate for the volume of the sample taken for quantification. Injections were carried out in triplicate. Then the masses of the released active agents were calculated using a mass balance. The cumulative release from the microcapsules suspension for each sampling time was calculated from the following equation: ${ }^{42}$

$$
\text { cumulative release }(\mathrm{CR} \%)=\frac{\mathrm{m}(\text { released })}{\mathrm{m}(\text { initial })} \times 100
$$

where $\mathrm{m}$ (released) is the mass of the released limonene or vanillin at a certain sampling time and $m$ (initial) is the initial mass of limonene or vanillin present in the microcapsules.

2.5. Grafting of Microcapsules on Fabrics. Citric acid was used as a nontoxic cross-linker to covalently join the wall material (chitosan/gum Arabic coacervates) onto the cotton fabrics by ester bonds. The procedure applied here is based on methods previously reported in the literature ${ }^{32,33}$ but with some modifications. The test fabrics were first immersed in a bath containing $10 \%(\mathrm{w} / \mathrm{v})$ of the microcapsules suspension, $3 \%(\mathrm{w} /$ 
v) of citric acid, and $1.5 \%(\mathrm{w} / \mathrm{v})$ of sodium phosphate monobasic monohydrate (used as catalyst).Thereafter it was heated at $50{ }^{\circ} \mathrm{C}$ for $5 \mathrm{~min}$. Fabrics were then washed thoroughly twice with deionized water and passed through a 2 roller foulard (Roaches EHP Padder) under 1 bar pressure at a speed rate of $3 \mathrm{~m} / \mathrm{min}$. Subsequently, fixation was achieved by placing the fabric samples in a thermofixation chamber (Roaches laboratory thermofixation oven, model Mini Thermo) with circulating air at a temperature of $90{ }^{\circ} \mathrm{C}$ for 2 min. After drying, the curing process was tested at two different conditions ( 120 and $150{ }^{\circ} \mathrm{C}$ for 3 and $2 \mathrm{~min}$, respectively). The wet pickup percentage of the impregnated samples ranged between $95 \%$ and $100 \%$ and was determined according to the following formula: ${ }^{37}$

$$
\text { wet pickup } \%(\mathrm{w} / \mathrm{w})=\frac{\operatorname{mass}(\text { wet fabric })-\operatorname{mass}(\text { dry fabric })}{\operatorname{mass}(\text { dry fabric })} \times 100
$$

where mass(dry fabric) was the sample mass before the impregnation and mass(wet fabric) was the sample mass after the foulard step, as described previously.

2.6. Characterization of Treated Fabrics. 2.6.1. SEM. A high-resolution (Schottky) environmental scanning electron microscope with X-ray microanalysis and electron backscattered diffraction analysis Quanta 400 FEG ESEM/EDAX Genesis $\mathrm{X} 4 \mathrm{M}$ operating at $15.00 \mathrm{kV}$ was used to examine the morphological features of the produced microcapsules grafted onto the fabrics. Samples were directly examined without being previously coated.

2.6.2. FTIR Spectroscopy. To examine the effectiveness of the grafting reaction, samples of microcapsules, citric acid, untreated cotton fabric (control), and impregnated cotton fabric were examined by FTIR. The microcapsules samples were separated from the original suspension by decantation and then freeze-dried before FTIR analysis. The analysis was conducted using a Jasco FT/IR-6800 spectrometer (Jasco Analytical Instruments, USA) equipped with a MIRacle single reflection ATR (attenuated total reflectance ZnSe crystal plate) accessory (PIKE Technologies, USA) and a TGS (triglycine sulfate) detector. Cosine apodization function was used to suppress leakage side lobes on the sampled signal. Spectra were acquired in absorbance mode using 56 scans at a resolution of 4 $\mathrm{cm}^{-1}$ in the range of $4000-500 \mathrm{~cm}^{-1}$. The fabrics, randomly sampled to ensure consistent analysis and reproducibility, were used as such.

2.7. Antibacterial Assays. 2.7.1. Agar Diffusion Method. This assay was conducted with the limonene and vanillin microcapsules suspensions after applying the washing procedure described previously. Moreover, the free active agents were also tested separately (not incorporated in microcapsules). Staphylococcus aureus (ATCC 19213) and Escherichia coli (ATCC 10536) were used as representatives for Gram positive and Gram negative bacteria, respectively. The bacterial inoculums were prepared, under aseptic conditions, by transferring four isolated colonies of each type to individual test tubes containing nutrient broth and then incubated at 37 ${ }^{\circ} \mathrm{C}$ for $24 \mathrm{~h}$. The inoculums were then diluted by sterilized Ringer solution to a concentration of $0.5 \mathrm{McF}$ arland turbidity (concentration of $(1.5-3.0) \times 10^{8} \mathrm{CFU} / \mathrm{mL}$ ). The concentration of the bacteria dilutions, also ascertained through UV spectrophotometry at $625 \mathrm{~nm}$, was 0.0938 for the S. aureus and 0.0940 for the E. coli. The bacterial solutions were then inoculated on the surface of Mueller-Hinton agar plates, using sterilized cotton swabs, and thereafter allowed to dry. Then, a well of $6 \mathrm{~mm}$ diameter was made in the center of each inoculated plate; the plug was removed and filled with $100 \mu \mathrm{L}$ of the microcapsules suspension. The limonene oil was diluted in dimethyl sulfoxide (DMSO) (7:3 ratio), and the vanillin dissolved in corn oil ( $0.03 \mathrm{~g}$ vanillin in $1 \mathrm{~g}$ of oil). The plates were incubated at $37^{\circ} \mathrm{C}$ for $24 \mathrm{~h}$. After this time period, the diameter of the inhibition zone was measured and incubation maintained for more than 4 days in order to evaluate further changes in the inhibition zone. The clear zone formed, after incubation, around each hole (inhibition halo) indicates antimicrobial activity, and its diameter is a measure of the inhibitory effect. All of the tests were done in duplicate.

2.7.2. Standard Test Method under Dynamic Contact Conditions. This test aimed at evaluating the antibacterial activity of the impregnated fabrics. It is based on the American Society for Testing and Materials (ASTM) designation E 214901 standard method, designed to analyze samples treated with nonleaching (substrate-bound) antimicrobial agents under dynamic contact conditions. ${ }^{43}$ In this work the bacterial inoculum was adjusted to $0.5 \mathrm{McF}$ arland turbidity standard (concentration of $(1.5-3.0) \times 10^{8} \mathrm{CFU} / \mathrm{mL}$ ) using sterilized Ringer solution. The concentration of the bacteria dilutions was measured spectrophotometrically at $625 \mathrm{~nm}$. This solution was then diluted in a sterile buffer of $0.3 \mathrm{mM} \mathrm{KH}_{2} \mathrm{PO}_{4}(\mathrm{pH}=7.2 \pm$ $0.1)$ to reach a concentration of $(1.5-3.0) \times 10^{5} \mathrm{CFU} / \mathrm{mL}$ and used as the working bacterial dilution employed in the assays. For the determination of bacterial inhibition, a fabric sample impregnated with the microcapsules $\left(2 \times 2 \mathrm{~cm}^{2}\right)$ was introduced into $50 \mathrm{~mL}$ of the working bacterial dilution placed in a sterile $250 \mathrm{~mL}$ flask. The flask was capped and placed in an orbital stirring bath at $37^{\circ} \mathrm{C}$. After $1 \mathrm{~min}$ of stirring, $1 \mathrm{~mL}$ of the solution was aseptically collected to determine bacterial concentration by the standard plate counting technique, which involves using serial dilutions and incorporation in Petri dishes with nutrient agar. The obtained value was considered as the bacteria concentration at the initial contact time $\left(t_{0}\right)$. After taking the sample, the flask was immediately returned to the bath and stirred for a further $15 \mathrm{~min}$. Then, a new sample of the solution was aseptically collected for bacteria counting. The results of colony counting were converted to colony forming units per milliliter $(\mathrm{CFU} / \mathrm{mL})$ and used to calculate the percentage of bacterial reduction. Two other flasks, one containing the untreated fabric sample (fabric without microcapsules) and another flask containing only the working bacterial dilution (without sample addition) and both submitted to the same procedure of colony counting and percentage of bacteria reduction determination, were used as control. After the first 15 min of testing, the inoculum solution of the treated fabric samples and the blank control were renewed and the sampling was repeated for bacteria counting at $30,45,60,75,90,105$, and 120 min time periods. Before renewal of the inoculum solution of the fabric sample, the sample was always washed with sterile deionized water. The step of the inoculum renewing (every $15 \mathrm{~min}$ ) is a modification of the original E 2149-01 standard and gives a better idea about the real amount of inhibition after that time of exposure. ${ }^{44}$ The percent of bacterial reduction upon contact with the fabric samples was calculated using the following equation: ${ }^{43}$

$$
\text { reduction }(\%)=\frac{A-B}{A} \times 100
$$


where $B$ is the $\mathrm{CFU} / \mathrm{mL}$ for the flask containing the treated fabric sample after the specified contact time and $A$ is the CFU/ $\mathrm{mL}$ for the flask containing the inoculum before the addition of the treated fabric.

\section{RESULTS AND DISCUSSION}

3.1. Characterization of Microcapsules. The hydrophilic-lipophilic balance (HLB) reflects the adequacy of the emulsifier to a certain application. Emulsifiers with low HLB values (4.7-6.7) are usually used to obtain w/o emulsions, whereas $\mathrm{o} / \mathrm{w}$ emulsions are obtained by emulsifiers with higher HLB values $(9.6-17.6){ }^{45}$ However, some articles in the literature reported microencapsulation processes by complex coacervation where low HLB value emulsifiers have been used (e.g., Span 83), ${ }^{40}$ this strategy being followed in this work where PGPR (HLB of 2-4) and Span 85 (HLB of 1.8$)^{46}$ have been chosen. The Span family emulsifiers are currently used in these types of microencapsulated systems. Concerning the PGPR, a biodegradable emulsifier manufactured from the esterification of castor oil fatty acids with polyglycerol is reported to have no potential threat to the environment. ${ }^{47}$ In addition, toxicological studies demonstrated that it does not have any health hazards. ${ }^{48}$

From optical microscopy analysis (Figure 1), it was possible to observe two main types of morphology (mono- and

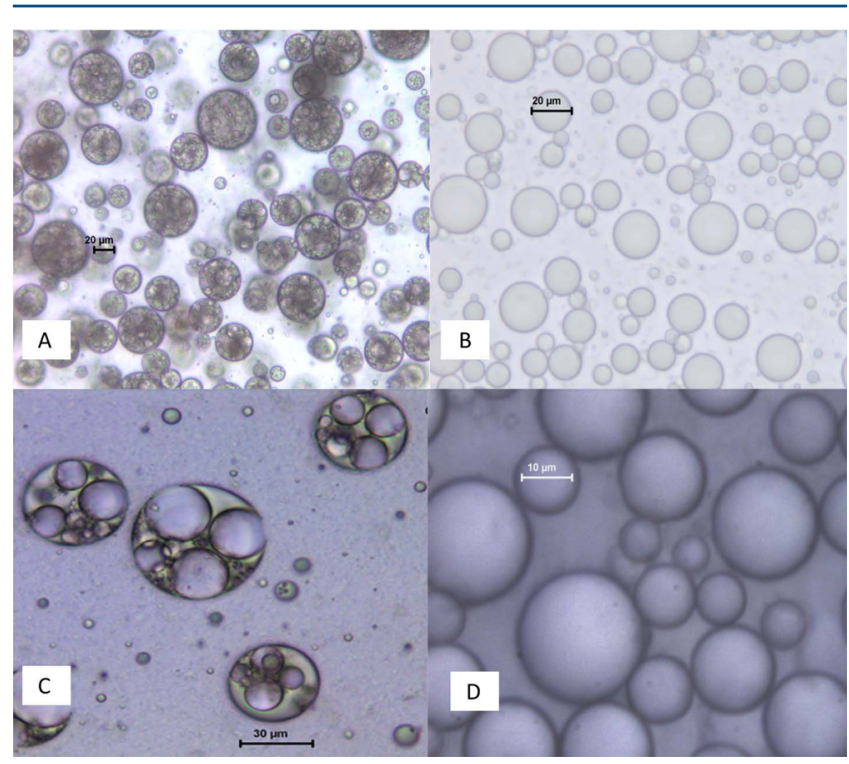

Figure 1. Optical microscope images of vanillin microcapsules of (A) formulation 1 produced by PGPR and (B) formulation 3 produced by Span 85 (magnification (A) 200× and (B) 400X); limonene microcapsules of (C) formulation 4 produced by PGPR and (D) formulation 6 produced by Span 85 (magnification (C) 400× and (D) $1000 \times)$.

polynuclear) depending on the type of emulsifier used. The ones prepared with PGPR presented a polynuclear morphology, whereas formulations prepared with Span 85 showed a mononuclear morphology, regardless of the type of the active agent.

Table 2 shows the mean diameters of the produced microcapsules, as well as the values obtained for the solid content and microencapsulation efficiency. The graphs of the differential and cumulative particle size distribution in volume are shown in Figures S1, S2 and S3. For the same amount and
Table 2. Mean Diameter, Solid Content, and Encapsulation Efficiencies of the Produced Microcapsules

\begin{tabular}{cccc} 
formulation & $\begin{array}{c}\text { mean diameter in volume } \\
(\mu \mathrm{m})\end{array}$ & $\begin{array}{c}\text { solid content } \\
(\% \mathrm{w} / \mathrm{w})\end{array}$ & $\begin{array}{c}\mathrm{EE} \% \\
(\% \mathrm{w} / \mathrm{w})\end{array}$ \\
1 & 15.7 & 28.3 & 95.7 \\
2 & 38.3 & 29.7 & 98.3 \\
3 & 10.4 & 25.4 & 100 \\
4 & 18.4 & 27.8 & 90.4 \\
5 & 39.0 & 28.8 & 94.1 \\
6 & 11.1 & 25.3 & 98.6 \\
\hline
\end{tabular}

type of core material, vanillin formulations 1 and 3 and limonene formulations 4 and 6 , the use of PGPR emulsifier produced microcapsules with larger average size than the corresponding Span 85 counterparts. In fact, the mean particle size changes from 15.7 to $10.4 \mu \mathrm{m}$ and from 18.4 to $11.1 \mu \mathrm{m}$ for vanillin and limonene formulations, respectively, when PGPR was replaced by Span 85 . The particle size distribution was also affected by the core material/wall ratio. In the present study, it was noticed that keeping the amount of wall materials constant and increasing the amount of core material (from 1 to $4.5 \mathrm{~g}$ ), i.e., by increasing the core material/wall material ratio (from 0.67 to 3 ), resulted in a significant increase of the determined mean diameter of the microcapsules (vanillin formulations 1 and 2 and limonene formulations 4 and 5, whose mean diameter increased from 15.7 to $38.3 \mu \mathrm{m}$ and 18.4 to $39.0 \mu \mathrm{m}$, respectively). The increase in the size of the microcapsules with increasing the core material/wall material ratio has been reported in the literature involving preparations by complex coacervation. ${ }^{39,40,49}$ Dong et al. ${ }^{46}$ explained this by stating that concerning the multinuclear microcapsules, the increase in the ratio core material/wall material results in an increased amount of emulsion droplets available in the suspension during the preparation, which subsequently forms larger spherical coacervate polynuclear microcapsules.

In what concerns the EE\%, it ranged between $90.4 \%$ and $100 \%$ as shown in Table 2 . The values are significantly higher than the ones reported by Pakzad et al. ${ }^{27}$ who obtained an EE\% falling in the range of $53-82 \%$ by using also tannic acid as a hardening agent for peppermint oil microencapsulation by complex coacervation using gum Arabic and gelatin, and Tween 80 as emulsifier. In this work, the best $\mathrm{EE} \%$ values were achieved with Span 80 (100\% and 98.6\%, respectively, for vanillin and limonene). These results are in agreement with those obtained by Rabisková et al. ${ }^{50}$ who stated that the use of emulsifiers with low HLB values (1.8 and 6.7) in the preparation of $\mathrm{o} / \mathrm{w}$ emulsions for complex coacervation results in higher values of $\mathrm{EE} \%$, indicating the preference of the encapsulation of hydrophobic materials for emulsifiers with low HLB value. The authors also reported the inability of emulsifiers with high HLB values, such as Tween 81 and Tween 80 (HLB = 10 and 15, respectively) to encapsulate oils by complex coacervation using gelatin and gum Arabic as wall materials.

Comparing the two used active agents, it was observed that formulations obtained using vanillin generally resulted in higher $\mathrm{EE} \%$, comparatively with the corresponding formulations using limonene. This might be due to the fact that vanillin was dissolved in corn oil (as viscous carrier) that might have decreased its diffusivity through the wall material. In contrast, in the case of limonene, it was directly used without the need of a solubilizing medium, hence diffusing more readily. 
3.2. Release Studies of Microcapsules. The cumulative release profiles of formulations 2, 4, and 6 are shown in Figure 2. It could be observed that the release profiles of the three

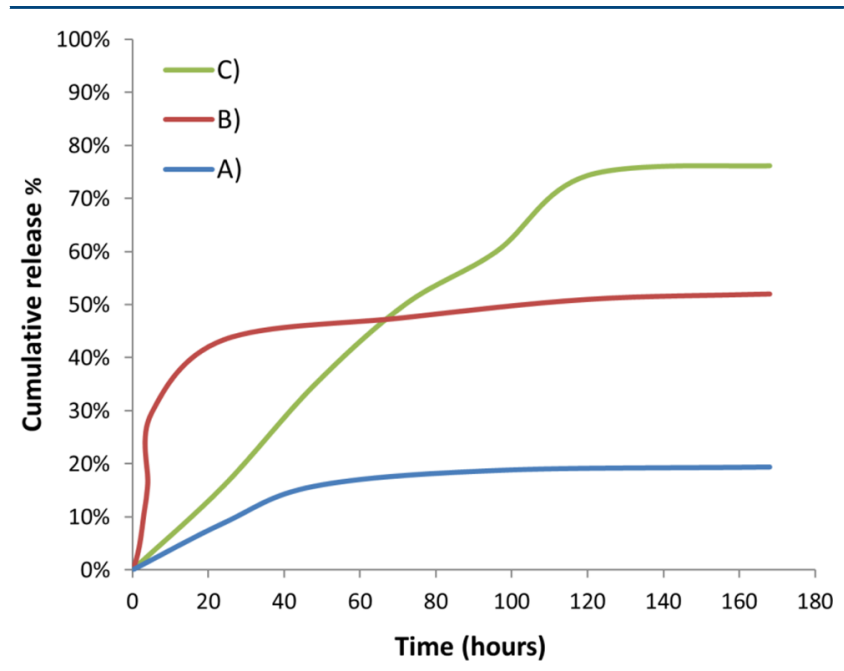

Figure 2. Cumulative release profiles of (A) vanillin in formulation 2 (PGPR), (B) limonene in formulation 4 (PGPR), and (C) limonene in formulation 6 (Span 85). Samples were incubated in $n$-hexane at 37 ${ }^{\circ} \mathrm{C}$ and $100 \mathrm{rpm}$.

formulations exhibited a two-stage behavior: first a phase characterized by a burst release effect and then followed by a slowly rising plateau pattern of gradual sustained release. ${ }^{51}$ The release profile of vanillin from the polynuclear microcapsules (formulation 2), in which PGPR was used as the emulsifier, was more prolonged than the limonene release from the microcapsules of formulation 4 (prepared with the same emulsifier (PGPR) thus having similar morphology). The faster release behavior of limonene in the first phase of the release pattern (before reaching the plateau) can be justified by the better affinity it presents with the release medium (hexane), comparatively with vanillin. In formulation 2 , the plateau was attained after $48 \mathrm{~h}$, whereby approximately $16 \%$ of the total encapsulated vanillin was released, whereas in formulation 4 the stable sustained release phase started earlier (after approximately $24 \mathrm{~h}$ ), whereby $43 \%$ of the incorporated limonene was released. Furthermore, it was observed that after 7 days (168 h), the vanillin total cumulative release reached $19.4 \%$, unlike limonene formulation 4 in which $52 \%$ was released within the first 7 days under the same conditions $\left(37^{\circ} \mathrm{C}\right.$ and $\left.100 \mathrm{rpm}\right)$. This slower release rate behavior is probably related to the chemical and structure differences between vanillin and limonene and their ability to diffuse through the polymer wall, added to the fact that vanillin, unlike limonene, was dissolved formerly in corn oil. The results obtained are in accordance with the vanillin slow and sustained release profile that was reported by Dalmolin et al. ${ }^{52}$ who used polylactic acid to encapsulate vanillin and obtained a biphasic slow pattern with $20 \%$ cumulative vanillin release after $120 \mathrm{~h}$.

By comparing the two release curves for limonene (formulations 4 and 6), it could be observed that a faster initial release was achieved with formulation 4 . Also, the stable sustained release phase started earlier (after almost $24 \mathrm{~h}$ ) in formulation 4 (Figure 2B), whereby $43 \%$ of the incorporated limonene was released. The same phase started in formulation 6 (Figure 2C) after $120 \mathrm{~h}$ (5 days) where about $74 \%$ of the encapsulated limonene was released. It is notable that after 7 days (168 h), at $37^{\circ} \mathrm{C}$ and $100 \mathrm{rpm}$, for both formulations, the overall cumulative release for the mononuclear microcapsules was about $75 \%$, whereas a value of $52 \%$ was achieved with the polynuclear microcapsules. In this context, it could be concluded that the release rate is lower in the polynuclear microcapsules than in the case of mononuclear microcapsules. These results are in agreement with those described by Jégat et al. ${ }^{53}$ who used different stirring speeds to produce mononuclear and polynuclear microcapsules and reported a lower release rate for the polynuclear ones. It has been also reported by Dong et al. that, comparative with mononuclear microcapsules, the polynuclear ones give rise to better controlled release behavior, making them more favorable for applications requiring prolonged release. ${ }^{14}$

3.3. Textile Impregnation Studies. SEM was used to examine the cotton fabrics impregnated with microcapsules of different formulations and grafted thermally with citric acid. Figure $3 \mathrm{~A}$ shows the fabric treated with vanillin microcapsules

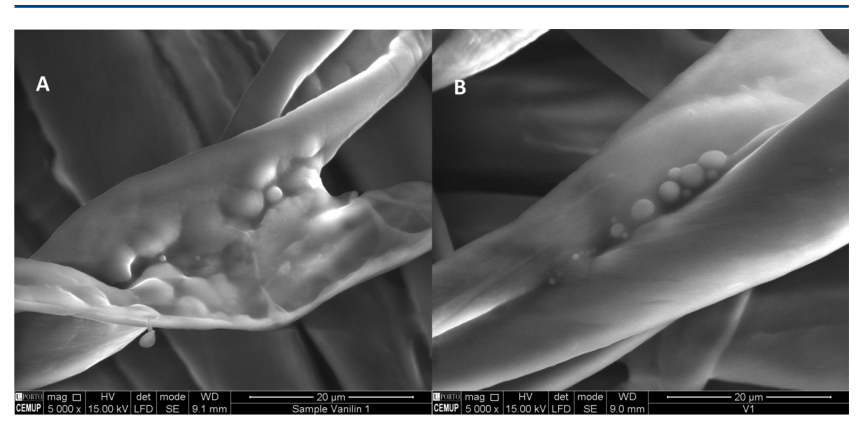

Figure 3. SEM images of fabrics impregnated with (A) vanillin microcapsules of formulation 1 cured at $120{ }^{\circ} \mathrm{C}$ for $3 \mathrm{~min}$ and (B) vanillin microcapsules of formulation 1 cured at $150{ }^{\circ} \mathrm{C}$ for $2 \mathrm{~min}$.

obtained from formulation 1 , dried at $90{ }^{\circ} \mathrm{C}$ for $2 \mathrm{~min}$ and cured at $120^{\circ} \mathrm{C}$ for $3 \mathrm{~min}$. It was observed that a thin film-like substance covers the microcapsules. This film was considerably less evident when the curing conditions were changed to 150 ${ }^{\circ} \mathrm{C}(2 \mathrm{~min})$ as shown in Figure $3 \mathrm{~B}$.

SEM image of fabrics treated with limonene microcapsules obtained from formulations 4 is shown in Figure S4. Despite the fact that both formulations 1 and 4 were prepared with the same amounts of PGPR (0.35 g) and the hardening agent tannic acid $(0.2 \mathrm{~g})$ and undergone the same drying conditions $\left(90{ }^{\circ} \mathrm{C}\right.$ for $\left.2 \mathrm{~min}\right)$ and curing $\left(120^{\circ} \mathrm{C}\right.$ for $\left.3 \mathrm{~min}\right)$, it could be observed that more vanillin microcapsules were effectively grafted on the fabric (Figure 3A) than the limonene ones (Figure S4). This suggests that formulation 1 is more thermally stable than formulation 4 .

Fabrics impregnated with formulations 3 and 6, formulations produced with Span 85 , did not show any attached microcapsules after the drying and curing steps $\left(90^{\circ} \mathrm{C}\right.$ for $2 \mathrm{~min}$ and $120{ }^{\circ} \mathrm{C}$ for $\left.3 \mathrm{~min}\right)$. However, some remnants of the microcapsules could be observed in the interstices between the fabric fibers as shown in Figure S5. This suggests that microcapsules prepared with Span 85 have a low thermal stability and were destroyed during thermal curing.

The most successful formulations were vanillin microcapsules according to formulation 2 and limonene microcapsules according to formulation 5 (Figure $4 \mathrm{~A}$ and Figure 4B, respectively), applying a temperature of $90{ }^{\circ} \mathrm{C}(2 \mathrm{~min})$ for thermofixation and curing temperature of $120{ }^{\circ} \mathrm{C}$ for $3 \mathrm{~min}$. These formulations presented higher solid content $(29.7 \%$ and 


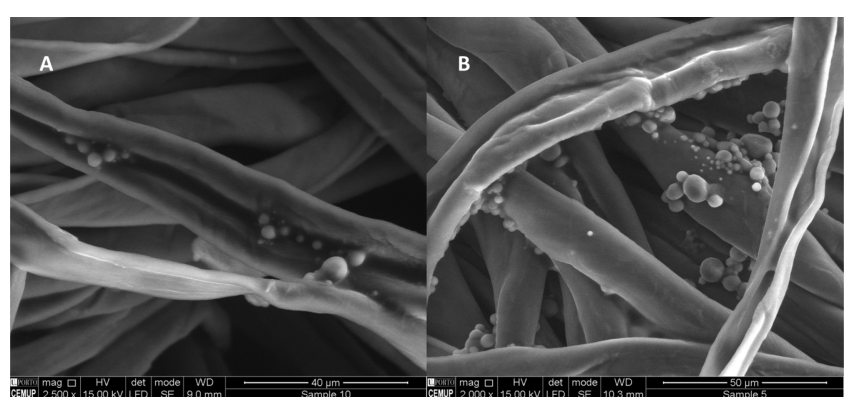

Figure 4. SEM images of fabrics impregnated with (A) vanillin microcapsules of formulation 2 and (B) limonene microcapsules of formulation 5 , both cured at $120{ }^{\circ} \mathrm{C}$ for $3 \mathrm{~min}$.

$28.8 \%$, respectively, for formulations 2 and 5), a fact that was associated with the used high amounts of PGPR and the presence of tannic acid as hardening agent, which resulted in microcapsule's improved thermal stability. It was also noticed that the increase of emulsifier together with the increase of core material (limonene oil or vanillin dissolved in corn oil) made the limonene formulation endure the treatment better than the vanillin one, contrary to what was previously observed with formulations 1 and 4 (formulations with lower amounts of emulsifier and core materials), where the vanillin formulation gave rise to better results than the limonene one. The impact was obviously perceptible in the amount of fixed microcapsules and their distribution. Although the curing was performed at the same temperature, the film that covered the microcapsules in the previous formulations did not appear in this last case (of formulatios 2 and 5), revealing the smooth appearance of the microcapsules surface. In contrast to the relatively wide size distribution of particle size of the grafted formulations (Figures S1 and S2), it was observed that the microcapsules grafted and retained on the textiles after curing were predominantly the ones of small size. This can be possibly attributed to the removal of the high size microcapsules during the washing step that was applied before the thermofixation and right after the reaction with citric acid. Monllor et al. reported a similar observation and concluded that the smaller microcapsules tend to remain on the fabrics after several washing cycles, whereas the larger ones are usually lost more quickly.

The concentration of citric acid has been reported in the literature to affect the degree of whiteness of the treated fabric, as well as the degree of the cross-linking reaction. ${ }^{33}$ In the present work and in order to guarantee the desired characteristics of the fabric, low concentrations of citric acid were used, even lower than the ones mentioned in the cited literature, ${ }^{32,33}$ as we took into consideration the low availability of functional groups (amino groups) on microcapsules surface due to its consumption during the complex coacervation process. No whiteness loss was observed by qualitative inspection. Moreover, the used concentration gave rise to well grafted microcapsules (Figure 4). Qualitative inspection has also shown that the fabrics remained pliable and flexible after the treatment. This is actually one of the advantages of applying chemical grafting over using polymeric binders to fix the microcapsules onto the fabrics. The chemical grafting has been reported to maintain the breathability and flexibility of the fabrics, in opposition to polymeric binders that are reported to change the tensile strength and elasticity, and decrease the flexibility, air permeability, and softness of the fabric. ${ }^{55,56}$
The effectiveness of the impregnation studies, namely, the occurrence of the grafting reaction between the cotton fabric and the microcapsules via the citric acid, was examined by FTIR. Figure 5 shows the spectra of the limonene micro-
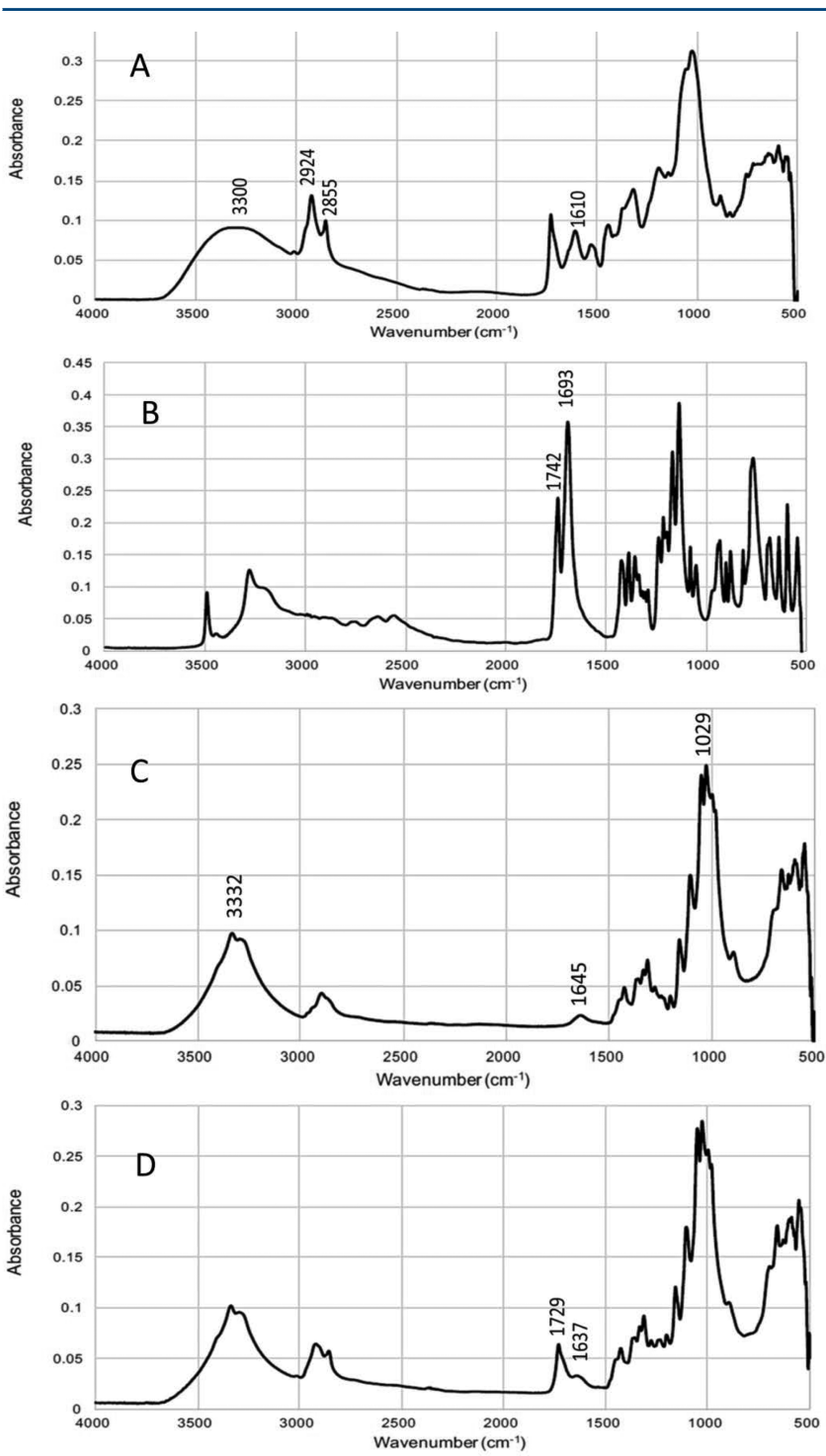

Figure 5. FTIR spectra of (A) microcapsules, (B) citric acid, (C) untreated cotton fabric, and (D) cotton fabric treated with limonene microcapsules.

capsules (freeze-dried samples from formulation 5), citric acid (cross-linker), untreated cotton fabric (control), and the treated cotton fabric (with formulation 5, cured at $120{ }^{\circ} \mathrm{C}$ for $3 \mathrm{~min}$ ). Table S1 lists the significant peaks of the spectra and their functional groups. ${ }^{32,38,55,57}$ The spectrum of the chitosan/ gum Arabic microcapsules loaded with limonene (Figure 5A) showed the presence of an important peak at $2855 \mathrm{~cm}^{-1}$. This peak was reported in the literature in the spectra of microcapsules prepared by complex coacervation between chitosan and gum Arabic. ${ }^{38,40}$ Additionally, the broad band centered at $3300 \mathrm{~cm}^{-1}$ is attributed to the $-\mathrm{OH}$ groups of both chitosan and gum Arabic overlapped with the $-\mathrm{NH}$ stretching of chitosan. This band can also represent the hydrogen bonds established between gum Arabic and chitosan. ${ }^{38}$ The spectrum of cotton fabric impregnated with limonene microcapsules 
(Figure 5D) has shown the disappearance of the sharp peaks at 1742 and $1693 \mathrm{~cm}^{-1}$ that previously appeared in the spectrum of the cross-linker citric acid (Figure 5B), which indicates that they had become involved in bonding, i.e., the esterification reaction between the carboxylic group of citric acid and the $-\mathrm{OH}$ group of the cotton cellulose. ${ }^{32}$ The spectrum of the grafted cotton fabric also revealed the appearance of a new peak of $\mathrm{C}=\mathrm{O}$ ester stretching at $1729 \mathrm{~cm}^{-1}$, which was not present in the control cotton fabric sample (Figure 5C). This peak confirms the covalent attachment between the polymeric shell of the microcapsules (of chitosan and gum Arabic) and cotton cellulose via citric acid through ester bond formation. ${ }^{58}$ Additionally, the presence of a peak at $1637 \mathrm{~cm}^{-1}$ with small intensity, which is assigned to the bending vibration of the $-\mathrm{NH}$ group, points to the chemical reaction between the residual free $-\mathrm{NH}_{2}$ groups of chitosan in the microcapsules shells and the $-\mathrm{COOH}$ groups of citric acid. ${ }^{32}$

These FTIR results are complemented by SEM images (Figure S6) of cotton fabrics impregnated with limonene microcapsules (formulation 5) after being washed with $2 \%$ commercial soap and $0.1 \mathrm{~N}$ acetic acid where the grafted microcapsules are clearly seen. This suggests not only successful grafting but also that the grafted microcapsules were not detached during the washing.

3.4. Evaluation of Antibacterial Activity. 3.4.1. Agar Diffusion. This assay was conducted to investigate the antibacterial activity of the free microcapsules before being grafted onto the fabrics. Figure 6 compares the results of the agar diffusion assay of the encapsulated core materials with the nonencapsulated ones. Table 3 lists the values of the measured diameters of the inhibition zones of the formulations after incubating the plates for $24 \mathrm{~h}$ and for 4 days; the results indicated that all the microcapsules formulations exhibited bacterial growth inhibition against both $S$. aureus and E. coli. It has been observed for the inhibition zones initially obtained for the nonencapsulated active agents (limonene or vanillin) that after 4 days of incubation, they have become covered with bacteria. In contrast, the bacterial effect of the encapsulated oil was maintained after 4 days of incubation under the same conditions. This sustainable antibacterial effect of the encapsulated limonene and vanillin in the examined microcapsules formulations is acquired as a result of the achieved controlled release and demonstrates the enhanced stability and prolonged antibacterial effect of the encapsulated core materials. The higher initial antibacterial effect that was exhibited by the nonencapsulated limonene oil dissolved in DMSO and manifested in the bigger zone of inhibition (as shown in Figure 6C and values in Table 3) might be related to the antibacterial activity of DMSO along with the limonene. ${ }^{59}$ Since the antibacterial effect of chitosan mainly depends on the presence of its positively charged amino groups freely to interact with the negative charges of the bacterial wall, ${ }^{60}$ it is important to mention that the antibacterial effect exhibited by the microcapsules is predominantly due to the encapsulated vanillin and limonene during their release trough the microcapsules wall (chitosan and gum Arabic) and not from the chitosan itself. This is because during the microcapsules preparation process by the complex coacervation method most of the positive amino groups of chitosan have been complexed with negative carboxylic groups of the gum Arabic to form the shell of the microcapsules.

3.4.2. Standard Test Method under Dynamic Contact Conditions. This bacterial reduction assay was conducted on

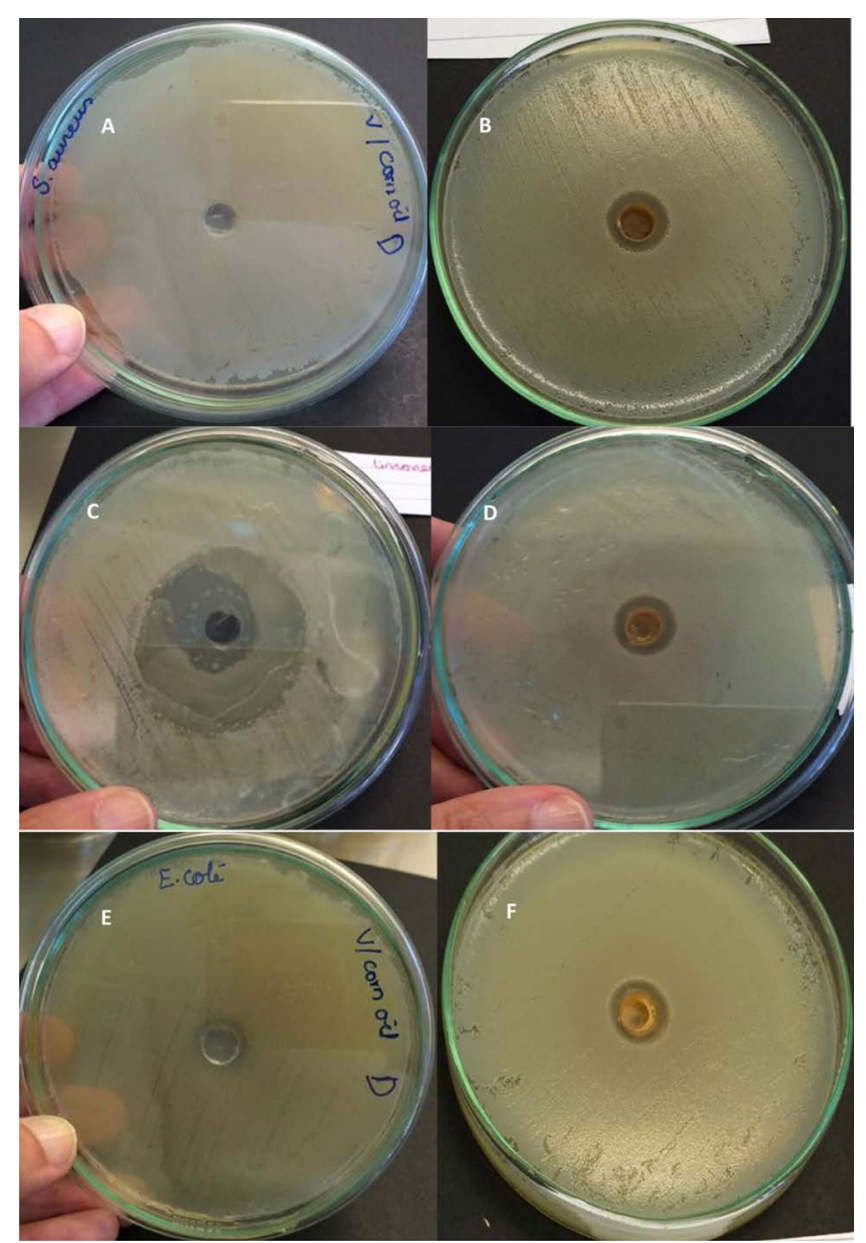

Figure 6. Zones of inhibition after $24 \mathrm{~h}$ of incubation of (A) nonencapsulated vanillin and (B) encapsulated vanillin against S.aureus, (C) nonencapsulated limonene in DMSO and (D) encapsulated limoene against S.aureus; (E) nonencapsulated vanillin and (F) encapsulated vanillin against $E$. coli.

cotton fabrics impregnated with vanillin microcapsules of formulation 2 and limonene microcapsules of formulation 5 (cured at $120{ }^{\circ} \mathrm{C}$ for $3 \mathrm{~min}$ ), as they gave good grafting outcome. The results of the assay are shown in Table 4 (more details are shown in Tables S2 and S3). It can be observed that both fabric samples exhibited an antibacterial activity against $E$. coli, whereby the fabric treated with limonene microcapsules showed $95.90 \%$ of bacterial reduction and the one impregnated with vanillin microcapsules showed $98.17 \%$ after $15 \mathrm{~min}$ of contact. A bacteriostatic activity is generally regarded if a reduction percentage between $90 \%$ and $99.9 \%$ of the total bacteria count $(\mathrm{CFU} / \mathrm{mL})$ in the original inoculum is obtained. ${ }^{44,61}$ As was mentioned previously, this assay involved the renewal of the bacterial inoculum at each sampling. In other words, every $15 \mathrm{~min}$ the fabric sample was withdrawn, washed thoroughly with sterilized water, and placed in contact with a new/fresh bacterial inoculum in order to take samples for colony counting. It is obvious from the obtained results that although the bacterial reduction percentage decreased with time, it was shown throughout the eight renewal cycles for both fabric samples. This antimicrobial effect is also evidence of the successful grafting of the prepared microcapsules to the fabric which as the results show have endured eight renewal cycles in contact with a highly concentrated inoculum solution. 
Table 3. Average Diameters of Inhibition Zones $(\mathrm{cm})$ of Limonene and Vanillin Microcapsules Suspensions and Free Oils in the Plate Test with E. coli and S. aureus $^{a}$

\begin{tabular}{|c|c|c|c|c|c|c|}
\hline & & & \multicolumn{2}{|c|}{ E. coli } & \multicolumn{2}{|c|}{ S. aureus } \\
\hline \multicolumn{3}{|c|}{ formulation } & after $24 \mathrm{~h}$ of incubation & after 4 days of incubation & after $24 \mathrm{~h}$ of incubation & after 4 days of incubation \\
\hline \multirow[t]{6}{*}{ core material } & vanillin & 1 & $1.45 \pm 0.21$ & $1.45 \pm 0.21$ & $1.45 \pm 0.07$ & $1.45 \pm 0.07$ \\
\hline & & 2 & $1.50 \pm 0.00$ & $1.55 \pm 0.07$ & $1.50 \pm 0.00$ & $1.55 \pm 0.07$ \\
\hline & & 3 & $0.80 \pm 0.00$ & $1.20 \pm 0.00$ & $1.55 \pm 0.07$ & $1.55 \pm 0.07$ \\
\hline & limonene & 4 & $1.25 \pm 0.08$ & $1.25 \pm 0.08$ & $1.50 \pm 0.13$ & $1.50 \pm 0.13$ \\
\hline & & 5 & $1.50 \pm 0.00$ & $1.50 \pm 0.00$ & $1.45 \pm 0.07$ & $1.45 \pm 0.07$ \\
\hline & & 6 & $1.25 \pm 0.40$ & $1.25 \pm 0.40$ & $1.35 \pm 0.07$ & $1.35 \pm 0.07$ \\
\hline \multirow{2}{*}{\multicolumn{3}{|c|}{$\begin{array}{l}\text { vanillin in corn oil } \\
\text { limonene in DMSO }\end{array}$}} & $0.95 \pm 0.32$ & $a$ & $1.00 \pm 0.20$ & $a$ \\
\hline & & & $3.30 \pm 0.31$ & $a$ & $3.30 \pm 0.18$ & $a$ \\
\hline
\end{tabular}

Table 4. Results of the Bacterial Reduction \% in the Dynamic Test of the Fabrics Impregnated with Vanillin and Limonene Microcapsules of Formulations 2 and 5, Respectively

\begin{tabular}{ccc} 
& \multicolumn{2}{c}{ bacterial reduction (\%) } \\
\cline { 2 - 3 } time (min) & vanillin & limonene \\
0 & 55.30 & 49.00 \\
15 & 98.17 & 95.90 \\
30 & 43.60 & 52.72 \\
45 & 35.51 & 43.70 \\
60 & 34.80 & 36.33 \\
75 & 30.63 & 35.92 \\
90 & 29.80 & 33.44 \\
105 & 29.50 & 33.03 \\
120 & 23.46 & 26.72 \\
\hline
\end{tabular}

\section{CONCLUSIONS}

The production of limonene and vanillin microcapsules was accomplished by means of the complex coacervation using gum Arabic and chitosan as shell materials and tannic acid as a green hardening agent. The type of the emulsifier used in the microcapsule preparation was found to have a significant influence on their size, morphology (being mononuclear or polynuclear), EE\%, and the release pattern of the core material through the wall. The release profile was affected by the type of core material and the morphology of the microcapsules. Among the different formulations that were prepared, it was confirmed that the multinuclear limonene and vanillin microcapsules obtained by $0.6 \mathrm{~g}$ of PGPR and $4.5 \mathrm{~g}$ of the core material are the ones that tolerated the thermofixation and curing conditions. This highlights the fact that some formulations, regardless of their high EE\% and uniform release profiles, were not suitable for the grafting reaction and could not survive its high temperature. The antibacterial assays of both the free microcapsules and the treated cotton fabrics have shown that they exhibited a sustained antibacterial activity.

\section{ASSOCIATED CONTENT}

\section{S Supporting Information}

The Supporting Information is available free of charge on the ACS Publications website at DOI: 10.1021/acs.iecr.7b00741.

Particle size distribution graphs, SEM images of fabrics impregnated with formulations 3, 4, and 6, SEM images of fabrics impregnated with formulation 5 after being washed, GC-FID chromatograms, table of wave numbers and functional groups of FTIR spectra, tables of results of antimicrobial assays (PDF)

\section{AUTHOR INFORMATION}

\section{Corresponding Authors}

*A.E.R.: e-mail, arodrig@fe.up.pt.

*T.S.: e-mail, T.Shoeib@aucegypt.edu.

ORCID $\odot$

Tamer Shoeib: 0000-0003-3512-1593

Notes

The authors declare no competing financial interest.

\section{ACKNOWLEDGMENTS}

This work was funded by a graduate student research grant provided by the American University in Cairo. This work was also in part financed by Project POCI-01-0145-FEDER006984, Associated Laboratory LSRE-LCM funded by FEDER funds through COMPETE2020, Programa Operacional Competitividade e Internacionalização (POCI) and by national funds through Fundação para a Ciência e a Tecnologia (FCT) in Portugal, NORTE-01-0145-FEDER-000006, funded by NORTE 2020, under PT2020 through ERDF. The authors thank Professor Dr. Joaquim Faria in the Department of Chemical Engineering at the University of Porto for his much appreciated help in conducting the FTIR analysis, and Catarina Moreira for her much appreciated technical help.

\section{REFERENCES}

(1) Holme, I. Innovative Technologies for High Performance Textiles. Color. Technol. 2007, 123, 59.

(2) Nelson, G. Application of Microencapsulation in Textiles. Int. J. Pharm. 2002, 242, 55.

(3) Panisello, C.; Peña, B.; Gilabert Oriol, G.; Constantí, M.; Gumí, T.; Garcia-Valls, R. Polysulfone/ Vanillin Microcapsules for Antibacterial and Aromatic Finishing of Fabrics. Ind. Eng. Chem. Res. 2013, 52, 9995.

(4) Rodrigues, S. N.; Martins, I. M.; Fernandes, I. P.; Gomes, P. B.; Mata, V. G.; Barreiro, M. F.; Rodrigues, A. E. Scentfashion ${ }^{\circledR}$ : Microencapsulated Perfumes for Textile Application. Chem. Eng. J. 2009, 149, 463.

(5) Specos, M. M. M.; García, J. J.; Tornesello, J.; Marino, P.; Vecchia, M. D.; Tesoriero, M. V. D.; Hermida, L. G. Microencapsulated Citronella Oil for Mosquito Repellent Finishing of Cotton Textiles. Trans. R. Soc. Trop. Med. Hyg. 2010, 104, 653.

(6) Ma, Z.; Yu, D.; Branford-White, C.; Nie, H.; Fan, Z.; Zhu, L. Microencapsulation of Tamoxifen: Application to Cotton Fabric. Colloids Surf., B 2009, 69, 85. 
(7) Flambard, X.; Bourbigot, S.; Kozlowski, R.; Muzyczek, M.; Mieleniak, B.; Ferreira, M.; Vermeulen, B.; Poutch, F. Progress in Safety, Flame Retardant Textiles and Flexible Fire Barriers for Seats in Transportation. Polym. Degrad. Stab. 2005, 88, 98.

(8) Son, K.; Yoo, D. I.; Shin, Y. Fixation of Vitamin E Microcapsules on Dyed Cotton Fabrics. Chem. Eng. J. 2014, 239, 284.

(9) Sánchez-silva, L.; Rodríguez, J. F.; Romero, A.; Sánchez, P. Preparation of Coated Thermo-Regulating Textiles Using RubithermRT31 Microcapsules. J. Appl. Polym. Sci. 2012, 124, 4809.

(10) Borreguero, A. M.; Talavera, B.; Rodriguez, J. F.; Valverde, J. L.; Gonzalez, J. L.; Carmona, M. Enhancing the Thermal Comfort of Fabrics for the Footwear Industry. Text. Res. J. 2013, 83, 1754.

(11) Smith, W. C., Ed. Smart Textile Coatings and Laminates; Woodhead Publishing Ltd.: Cambridge, U.K., 2010.

(12) Moreira, A. C. G.; Martins, I. M.; Fernandes, I.; Barreiro, M. F.; Rodrigues, A. E. Microencapsulation of Red and White Thyme Oil in Poly(Lactic-Co-Glycolic) Acid: Assessment of Encapsulation Efficiency and Antimicrobial Capacity of the Produced Microcapsules. Can. J. Chem. Eng. 2016, 94, 469.

(13) Nazzaro, F.; Orlando, P.; Fratianni, F.; Coppola, R. Microencapsulation in Food Science and Biotechnology. Curr. Opin. Biotechnol. 2012, 23, 182.

(14) Dong, Z. J.; Touré, A.; Jia, C. S.; Zhang, X. M.; Xu, S. Y. Effect of Processing Parameters on the Formation of Spherical Multinuclear Microcapsules Encapsulating Peppermint Oil by Coacervation. J. Microencapsulation 2007, 24, 634.

(15) Martins, I. M. Microencapsulation of Thyme Oil by Coacervation: Production, Characterization and Release Evaluation. Ph.D. Dissertation, University of Porto, Portugal, 2012.

(16) Su, J.; Wang, L.; Ren, L. Fabrication and Thermal Properties of MicroPCMs: Used Melamine-Formaldehyde Resin as Shell Material. J. Appl. Polym. Sci. 2006, 101, 1522.

(17) Salaün, F.; Lewandowski, M.; Vroman, I.; Bedek, G.; Bourbigot, S. Development and Characterisation of Flame-Retardant Fibres from Isotactic Polypropylene Melt-Compounded with Melamine-Formaldehyde Microcapsules. Polym. Degrad. Stab. 2011, 96, 131.

(18) Cogliano, V. J.; Grosse, Y.; Baan, R. A.; Straif, K.; Secretan, M. B.; El Ghissassi, F. Meeting Report: Summary of IARC Monographs on Formaldehyde, 2-Butoxyethanol, and 1-tert-Butoxy-2-Propanol. Environ. Health Perspect. 2005, 113, 1205.

(19) Hebeish, A.; Abdel-Mohdy, F.; Fouda, M. M. G.; Elsaid, Z.; Essam, S.; Tammam, G. H.; Drees, E. A. Green Synthesis of Easy Care and Antimicrobial Cotton Fabrics. Carbohydr. Polym. 2011, 86, 1684.

(20) Shahid-ul-islam, M.; Shahid, F.; Mohammad, F. Green Chemistry Approaches to Develop Antimicrobial Textiles Based on Sustainable Biopolymers-A Review. Ind. Eng. Chem. Res. 2013, 52, 5245 .

(21) Oliveira, B. F.; Santana, M. H. A.; Ré, M. I. Spray-Dried Chitosan Microspheres Cross-Linked with d,l-Glyceraldehyde as a Potential Drug Delivery System: Preparation and Characterization. Braz. J. Chem. Eng. 2005, 22, 353.

(22) Xiao, Z.; Li, W.; Zhu, G. Effect of Wall Materials and Core Oil on the Formation and Properties of Styralyl Acetate Microcapsules Prepared by Complex Coacervation. Colloid Polym. Sci. 2015, 293, 1339.

(23) Xiao, Z.; Liu, W.; Zhu, G.; Zhou, R.; Niu, Y. A Review of the Preparation and Application of Flavour and Essential Oils Microcapsules Based on Complex Coacervation Technology. J. Sci. Food Agric. 2014, 94, 1482.

(24) Dong, Z.; Xia, S.; Hua, S.; Hayat, K.; Zhang, X.; Xu, S. Optimization of Cross-Linking Parameters during Production of Transglutaminase-Hardened Spherical Multinuclear Microcapsules by Complex Coacervation. Colloids Surf., B 2008, 63, 41.

(25) Gouin, S. Microencapsulation: Industrial Appraisal of Existing Technologies and Trends. Trends Food Sci. Technol. 2004, 15, 330.

(26) Xing, F.; Cheng, G.; Yang, B.; Ma, L. Microencapsulation of Capsaicin by the Complex Coacervation of Gelatin, Acacia and Tannins. J. Appl. Polym. Sci. 2004, 91, 2669.
(27) Pakzad, H.; Alemzadeh, I.; Kazemi, A. Encapsulation of Peppermint Oil with Arabic Gum-Gelatin by Complex Coacervation Method. Int. J. Eng. 2013, 26, 807.

(28) Zhang, L.; Cheng, L.; Jiang, L.; Wang, Y.; Yang, G.; He, G. Effects of Tannic Acid on Gluten Protein Structure, Dough Properties and Bread Quality of Chinese Wheat. J. Sci. Food Agric. 2010, 90, 2462.

(29) Aracil, M. Á; Bou-Belda, E.; Monllor, P.; Gisbert, J. Binder Effectiveness of Microcapsules Applied onto Cotton Fabrics during Laundry. J. Text. Inst. 2016, 107, 300.

(30) Murugesh Babu, K.; Ravindra, K. B. Bioactive Antimicrobial Agents for Finishing of Textiles for Health Care Products. J. Text. Inst. 2015, 106, 706

(31) Miro Specos, M. M. M.; Escobar, G.; Marino, P.; Puggia, C.; Tesoriero, M. V.; Hermida, L. Aroma Finishing of Cotton Fabrics by Means of Microencapsulation Techniques. J. Ind. Text. 2010, 40, 13.

(32) Yang, Z.; Zeng, Z.; Xiao, Z.; Ji, H. Preparation and Controllable Release of Chitosan/Vanillin Microcapsules and their Application to Cotton Fabric. Flavour Fragrance J. 2014, 29, 114.

(33) Fan, F.; Zhang, W.; Wang, C. Covalent Bonding and Photochromic Properties of Double-Shell Polyurethane-Chitosan Microcapsules Crosslinked onto Cotton Fabric. Cellulose 2015, 22, 1427.

(34) Hebeish, A.; El-Naggar, M.; Fouda, M. M. G.; Ramadan, M. A.; Al-Deyab, S.; El-Rafie, M. Highly Effective Antibacterial Textiles Containing Green Synthesized Silver Nanoparticles. Carbohydr. Polym. 2011, 86, 936.

(35) Li, L.; Au, W.; Hua, T.; Zhao, D.; Wong, K. Improvement in Antibacterial Activity of Moxa Oil Containing Gelatin-Arabic Gum Microcapsules. Text. Res. J. 2013, 83, 1236.

(36) Sundrarajan, M.; Rukmani, A. Durable Antibacterial Finishing on Cotton by Impregnation of Limonene Microcapsules. Adv. Chem. Lett. 2013, 1, 40.

(37) Rodrigues, S. N.; Fernandes, I.; Martins, I. M.; Mata, V. G.; Barreiro, F.; Rodrigues, A. E. Microencapsulation of Limonene for Textile Application. Ind. Eng. Chem. Res. 2008, 47, 4142.

(38) Butstraen, C.; Salaün, F. Preparation of Microcapsules by Complex Coacervation of Gum Arabic and chitosan. Carbohydr. Polym. 2014, 99, 608.

(39) Xiao, Z.; Liu, W.; Zhu, G.; Zhou, R.; Niu, Y. Production and Characterization of Multinuclear Microcapsules Encapsulating Lavender Oil by Complex Coacervation. Flavour Fragrance J. 2014, 29, 166.

(40) Yang, Z.; Peng, Z.; Li, J.; Li, S.; Kong, L.; Li, P.; Wang, Q. Development and Evaluation of Novel Flavour Microcapsules Containing Vanilla Oil Using Complex Coacervation Approach. Food Chem. 2014, 145, 272.

(41) Rodrigues, S. N. Microencapsulation of Perfumes for Application in Textile Industry. Ph.D. Dissertation, University of Porto, Portugal, 2010.

(42) Chen, M.; Hu, Y.; Zhou, J.; Xie, Y.; Wu, H.; Yuan, T.; Yang, Z. Facile Fabrication of Tea Tree Oil- Loaded Antibacterial Microcapsules by Complex Coacervation of Sodium Alginate/ Quaternary Ammonium Salt of Chitosan. RSC Adv. 2016, 6, 13032

(43) American Society for Testing and Materials. Standard Test Method for Determining the Antimicrobial Activity of Immobilized Antimicrobial Agents under Dynamic Contact Conditions; ASTM International: West Conshohocken, PA, 2001; ASTM E2149-01.

(44) Fernandes, I. P.; Amaral, J. S.; Pinto, V.; Ferreira, M. J.; Barreiro, M. F. Development of Chitosan-Based Antimicrobial Leather Coatings. Carbohydr. Polym. 2013, 98, 1229.

(45) Zhang, L.; Que, G. Influence of the HLB Parameter of Surfactants on the Dispersion Properties of Brine in Residue. Colloids Surf., A 2008, 320, 111.

(46) Dong, Z.; Ma, Y.; Hayat, K.; Jia, C.; Xia, S.; Zhang, X. Morphology and Release Profile of Microcapsules Encapsulating Peppermint Oil by Complex Coacervation. J. Food Eng. 2011, 104, 455 .

(47) Kunduru, K. R.; Basu, A.; Haim Zada, M.; Domb, A. J. Castor Oil- Based Biodegradable Polyesters. Biomacromolecules 2015, 16, 2572. 
(48) Wilson, R.; van Schie, B. J.; Howes, D. Overview of the Preparation, Use and Biological Studies on Polyglycerol Polyricinoleate (PGPR). Food Chem. Toxicol. 1998, 36, 711.

(49) Comunian, T. A.; Thomazini, M.; Alves, A. J. G.; de Matos Junior, F. E.; de Carvalho Balieiro, J. C.; Favaro-Trindade, C. S. Microencapsulation of Ascorbic Acid by Complex Coacervation: Protection and Controlled Release. Food Res. Int. 2013, 52, 373.

(50) Rabisková, M.; Valásková, J. The Influence of HLB on the Encapsulation of Oils by Complex Coacervation. J. Microencapsulation 1998, 15, 747 .

(51) Lakkis, J. M. Encapsulation and Controlled Release Technologies in Food Systems; Blackwell Publishing: Ames, IA, 2007.

(52) Dalmolin, L. F.; Khalil, N. M.; Mainardes, R. M. Delivery of Vanillin by Poly(Lactic-Acid) Nanoparticles: Development, Characterization and In Vitro Evaluation of Antioxidant Activity. Mater. Sci. Eng., C 2016, 62, 1.

(53) Jégat, C.; Taverdet, J. L. Stirring Speed Influence Study on the Microencapsulation Process and on the Drug Release from Microcapsules. Polym. Bull. 2000, 44, 345.

(54) Monllor, P.; Capablanca, L.; Gisbert, J.; Díaz, P.; Montava, I.; Bonet, Á. Improvement of Microcapsule Adhesion to Fabrics. Text. Res. J. 2010, 80, 631.

(55) Salaün, F.; Vroman, I.; Elmajid, I. A Novel Approach to Synthesize and to Fix Microparticles on Cotton Fabric. Chem. Eng. J. 2012, 213, 78

(56) Salaün, F.; Devaux, E.; Bourbigot, S.; Rumeau, P. Thermoregulating Response of Cotton Fabric Containing Microencapsulated Phase Change Materials. Thermochim. Acta 2010, 506, 82.

(57) Liu, J.; Liu, C.; Liu, Y.; Chen, M.; Hu, Y.; Yang, Z. Study on the Grafting of Chitosan-Gelatin Microcapsules onto Cotton Fabrics and its Antibacterial Effect. Colloids Surf., B 2013, 109, 103.

(58) Alonso, D.; Gimeno, M.; Olayo, R.; Vázquez-Torres, H.; Sepúlveda-Sánchez, J. D.; Shirai, K. Cross-Linking Chitosan into UVIrradiated Cellulose Fibers for the Preparation of AntimicrobialFinished Textiles. Carbohydr. Polym. 2009, 77, 536.

(59) Basch, H.; Gadebusch, H. H. In Vitro Antimicrobial Activity of Dimethylsulfoxide. Appl. Microbiol. 1968, 16, 1953.

(60) Martínez-Camacho, A. P.; Cortez-Rocha, M.; Ezquerra-Brauer, J.; Graciano-Verdugo, A.; Rodriguez-Félix, F.; Castillo-Ortega, M.; Yépiz-Gómez, M. S.; Plascencia-Jatomea, M. Chitosan Composite Films: Thermal, Structural, Mechanical and Antifungal Properties. Carbohydr. Polym. 2010, 82, 305.

(61) Pankey, G. A.; Sabath, L. D. Clinical Relevance of Bacteriostatic versus Bactericidal Mechanisms of Action in the Treatment of GramPositive Bacterial Infections. Clin. Infect. Dis. 2004, 38, 864. 